\title{
Resolving the Fontan paradox: Addressing socioeconomic and racial disparities in patients with a single ventricle
}

\author{
Tara Karamlou, MD, ${ }^{\mathrm{a}}$ Shabnam Peyvandi, MD, ${ }^{\mathrm{b}}$ Myke Federman, MD, ${ }^{\mathrm{c}}$ Donna Goff, MD, MS, ${ }^{\mathrm{d}}$ \\ Raghav Murthy, MD, ${ }^{e}$ and S. Ram Kumar, MD, PhD, ${ }^{\mathrm{f}}$ for the members of the Southwest Congenital Cardiac \\ Consortium
}

\footnotetext{
From the ${ }^{\mathrm{a} D i v i s i o n}$ of Pediatric Cardiac Surgery, Phoenix Children's Hospital, Phoenix, Ariz; ${ }^{\mathrm{b}}$ Department of Pediatric Cardiology, University of California, San Francisco, San Francisco, Calif; ${ }^{\circ}$ Department of Pediatric Critical Care, University of California, Los Angeles, Los Angeles, Calif; ${ }^{\mathrm{d} D e p a r t m e n t}$ of Pediatric Cardiology, Loma Linda Children's Hospital, Loma Linda, Calif; eDivision of Pediatric Cardiac Surgery, Rady Children's Hospital, University of California, San Diego, San Diego, Calif; and ${ }^{\mathrm{f}}$ Division of Cardiac Surgery, University of Southern California and Heart Institute, Children's Hospital of Los Angeles, Los Angeles, Calif.

Members of the Southwest Congenital Cardiac Consortium are listed in the Acknowledgments.

Received for publication Aug 2, 2017; revisions received Oct 13, 2017; accepted for publication Nov 9, 2017; available ahead of print Feb 6, 2018.

Address for reprints: Tara Karamlou, MD, Division of Pediatric Cardiac Surgery, Phoenix Children's Hospital, Heart Center, Main Building, 1919 E Thomas Rd, Phoenix, AZ 85016 (E-mail: tarakaramlou@gmail.com). J Thorac Cardiovasc Surg 2018; 155:1727-31 $0022-5223 / \$ 36.00$

Copyright (C) 2017 by The American Association for Thoracic Surgery https://doi.org/10.1016/j.jtcvs.2017.11.103
}

Feature Editor's Note-The Fontan operation, in many respects, is the signature operation for congenital heart surgeons. At our Heart Center, palliative operations leading up to the Fontan procedure, the Fontan procedure itself, and post-Fontan surgical interventions account for $20 \%$ of our congenital cardiac surgery case volume. Over the past 45 years, the Fontan operation has evolved steadily with numerous technical modifications as surgeons have sought to improve patient outcomes. The resources and attention devoted by heart centers to the totality of care of Fontan patients is enormous. In a recent issue of The Journal of the American College of Cardiology, Atz and colleagues from the Pediatric Heart Network Investigators reported on nearly 500 patients undergoing a thorough health assessment 9 years after their previous landmark Fontan crosssectional study. The authors noted a concerning finding in these patients: Exercise performance decreased over the years and this was associated with worse functional health status. We are fortunate to present an invited expert opinion summarizing and augmenting this article by Yves d'Udekem. d'Udekem is a passionate advocate for Fontan patients. He is the founder and chair of the Australian and New Zealand Fontan Registry. He estimates that there are currently 70,000 patients with a Fontan circulation. d'Udekem has reviewed the findings of Atz and colleagues and added to this his own extensive experience with the very robust Australian and New Zealand Fontan Registry. That comprehensive database goes back 35 years, and they have found that a high level of physical activity and exercise training optimizes outcomes after the Fontan procedure. This analysis will performance.

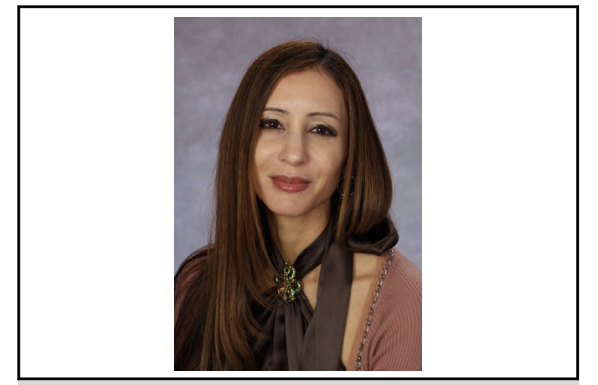

Tara Karamlou, MD

\section{Central Message}

We examine the third update from the ongoing Fontan Cross-sectional Study, which investigates the relationship between laboratory measures of systemic ventricular performance and functional status.

See Editorial Commentary page 1732.

further advance steps we can take to improve the lives of this complex cohort of patients.

\section{Carl L. Backer, MD}

A third progress update from the ongoing Fontan Crosssectional Cohort Study (Fontan 1) investigating the relationship between laboratory measures of systemic ventricular performance and functional status was recently presented by Atz and colleagues. ${ }^{1}$ The authors reported on transplant-free survival in 373 of the original study patients ( $80 \%$ of the cohort) at 9.4 years following Fontan 1. Functional status was measured by protocolized exercise testing coupled with standardized questionnaires, including the Peds Quality of Life Inventory and the Child Health Questionnaire. Echocardiography and B-type natriuretic peptide were used to chronically track ventricular performance. Multivariable regression analyses were used to identify determinants of both time-related transplant-free survival and increased functional health status or ventricular

Based on their results, the authors provided several rather pessimistic conclusions. Despite overall good survival (90\% at 9.4 years), there was a steady attrition in transplant-free survival. Moreover, the steady decline in survival was accompanied by decreasing exercise performance within nearly all parameters and worsening functional status. 
Unfortunately, these results resonate with recent multicenter reports from the Society of Thoracic Surgeons Congenital Heart Surgery Database and others. ${ }^{2-4}$ Somewhat surprisingly, few of the expected patient-level variables were informative regarding time-related survival, including older age at Fontan and lower functional status at Fontan 1. Moreover, neither ventricular morphology (left vs right) nor Fontan connection type was associated with survival. It is likely that the design of Fontan 1 (ie, enrollment only of Fontan survivors) introduced important selection bias, thereby contributing to these conclusions. That is to say, the exclusion of patients dying before Fontan omits the majority of attrition among those with systemic right ventricles and therefore selects a more favorable subset of patients with hypoplastic left heart syndrome. Similarly, only the survivors of atriopulmonary Fontan were included, leading to a study cohort with disproportionately good outcomes.

These issues notwithstanding, a critical finding that is incompletely addressed in this article was that higher family income decreased the risk of death or transplantation. These data resonate with the increasing body of literature (much within the single-ventricle population) that underscores the important relationship between socioeconomic (SES) and racial factors and clinical outcomes. ${ }^{5-11}$ Unfortunately, Atz and colleagues ${ }^{1}$ did not include dedicated metrics to investigate the role of SES factors (ie, Hollingshead Four Factor Score, maternal education, or poverty level) in outcomes, although the authors did include race and insurance status in their calculus. Furthermore, the findings reported for health care coverage, health care use, racial factors, and education level are flawed, biased, or wholly inadequate. This highlights that among the greatest challenges to investigating SES in congenital heart disease (CHD) is that the study variables chosen (or not chosen) for analysis may obfuscate critical relationships and underestimate the influence of SES and race. ${ }^{5-11}$

\section{PRECEDENT FOR IMPORTANCE OF SES FACTORS IN PATIENTS WITH A SINGLE VENTRICLE}

SES is defined as “an individual's or group's position within a hierarchical social structure," ${ }^{12}$ but is in truth difficult to measure. SES is probably best conceptualized as a composite that includes economic, sociologic, and racial factors that represent the position of an individual or group in relation to others based on income, education, and occupation. The importance of SES factors as a determinant of clinical outcomes (especially among patients with a single ventricle) has only recently become widely reported. Large, population-based studies in recent years have suggested racial/ethnic differences in survival after surgery for CHD (Shabnam Peyvandi, personal communication, 2017). ${ }^{6-11,13-17}$ In particular, there appears to be increased odds of mortality in black and Hispanic patients undergoing congenital heart surgery compared with white patients (Shabnam Peyvandi, personal communication, 2017). ${ }^{13-17}$ Going beyond mortality, SES appears to influence morbidities such as neurodevelopmental outcomes. The Boston Circulatory Arrest Trial, which utilized a comprehensive SES composite score (Hollingshead Four Factor Score) demonstrated that lower SES is associated with worse neurodevelopmental outcomes at age 16 years. ${ }^{18}$ In turn, neurodevelopmental status can certainly have an influence on functional status and quality of life as these children transition into independence.

\section{CLARITY OR OBSCURITY-THE SOCIOECONOMIC FONTAN PARADOX}

Within this context, let us dissect a bit more carefully the analysis of SES factors and their relationships in the article by Atz and colleagues. ${ }^{1}$ Regarding the indifference of insurance status, it is surprising that $96 \%$ of the cohort had health insurance, which seems contrary to general experience with adult CHD populations. A significant proportion of adult CHD patients are unemployed (33\%) and many are neurodevelopmentally or physically challenged. ${ }^{3,19}$ Moreover, many lack an organized transition to ongoing cardiac care, either due to individual barriers or lack of adequate health care delivery systems that support transition. The authors' finding of near-universal coverage is likely due to the fact that only a dichotomous factor (private vs public) to assess insurance status (rather than inclusion of both primary and secondary insurance) was utilized, ${ }^{1}$ which severely limits the validity of inferences correlating insurance with economic viability. In other words, almost all patients will qualify for public insurance $(94 \%$ of the children in California qualify for Medicaid ${ }^{20}$ ), and therefore this becomes an insensitive metric to assess either individual monetary resources or access to high-quality health care and services. In support of this presumption is the fact that higher income was protective of mortality but "private" insurance, which ostensibly would surrogate affluence, was unrelated. The assessment of "health care use" by the authors is similarly insensitive at best and misleading at worst given the highly selected nature of the population. Only $32 \%$ of patients in the study visited an adult congenital cardiologist, and only $35 \%$ visited an adult cardiologist within a 2-year period. Although this schedule of surveillance would seem to be inadequate considering the severity of cardiac disease, it is equally troubling that within a cohort in which age circumscribes the transition period in care from the pediatric realm to the adult realm, formal questions regarding the transition process remain unclear.

What about the assessment of racial factors? One might hypothesize that patients from disadvantaged ethnic groups have comparatively worse outcomes than whites. However, these questions are, in our opinion, unanswerable with this cohort. It is well known that most clinical studies tend to 
TABLE 1. List of potential factors to assess socioeconomic and racial status

\begin{tabular}{l}
\hline Major factors \\
Race (black/white/Hispanic/Asian) \\
Geographic location (Northeast/South/West) \\
Quintiles of household income \\
Absolute and relative poverty measures (federal poverty thresholds) \\
Highest maternal/paternal education level \\
Highest patient education level (if adult) \\
Patient occupation (if adult) \\
Unemployment duration (if unemployed) \\
Minor factors \\
Language development/language acquisition \\
Literacy development \\
Home environment (single parent/family size) \\
Neighborhood class (suburban/urban/rural) \\
Primary and secondary school characteristics (private/public) \\
Subjective social status measures \\
\hline
\end{tabular}

recruit white, predominantly educated subjects, biasing the results against finding a relationship between underrepresented ethnicities and outcome. Predictably, the majority $(80 \%)$ of patients in the Fontan cohort were white with only $9 \%$ black patients. Hispanic patients, who our group has found to be particularly at risk for poor outcome, ${ }^{5}$ were not specifically referenced in this study. Thus, the true effects of race/ethnicity may be difficult to ascertain in a biased population, and one should interpret the conclusions of these authors with caution. A corollary to this is that exercise programs were suggested as a potential key element to mitigating the universal decrease across the spectrum of functional outcomes reported. The protective influence of higher income level may therefore be related to the ability of more affluent individuals to adopt healthier lifestyles that include physical activity and a balanced diet. Although body mass index was not assessed, there is convincing data linking obesity to worse outcomes within Fontan patients ${ }^{21}$ as well as data linking obesity to lower SES status and specific ethnic groups. ${ }^{22}$ As articulated by Maslow in his classic psychological description of the hierarchical pyramid of needs, ${ }^{13}$ physiologic needs (ie, food, water, and shelter) supersede safety needs (eg, health and well-being); in this vein, participation in an exercise program and consuming healthier food is dependent on adequate (even luxurious) resource ${ }^{23}$ - both of which are unlikely to reliably exist in an underresourced Fontan population. In fairness to Atz and colleagues, ${ }^{1}$ we acknowledge that the potential lack of generalizability is an unavoidable circumstance of clinical research, and simply underscores the need to actively and aggressively seek methods to encourage socioeconomic and racial diversity within study populations.

Finally, the authors did not assess the education levels of the parents or the patients at the time of the Fontan 3 study or in the prior Fontan studies. As described originally by Braverman and colleagues, ${ }^{13}$ education level and income level are not interchangeable because earnings can vary at similar education levels. In turn, education level appears to be a strong indicator of socioeconomic disparity in health-related outcomes. ${ }^{13}$ Thus, assessment of income alone is not adequate to identify potential health-related SES disparities. In addition, one must take into account SES across the lifespan, particularly in this population of transitioning adults. For example, parent education levels can have a downstream effect on their children's earnings, occupation, and health in adult years. Preliminary population-based analyses in the State of California suggest that maternal education plays a significant role in the number of hospital readmissions during the first year of life after neonatal cardiac surgery (Shabnam Peyvandi, personal communication, 2017).

Taken together, all of these factors can contribute to a general underrepresentation of SES factors in many studies in CHD. Although investigators endeavor to clarify these relationships, selection and participation bias coupled with inadequate data granularity and inappropriate use of surrogate variables creates a paradox in which the very relationships we seek to unveil become further obscured.

Table 1 provides a list of possible factors that can be used by clinicians and scientists to more comprehensively assess socioeconomic and racial disparities within CHD populations. This is not an exhaustive list; rather, it is focused with an eye toward pragmatism in ascertainment and historical importance. Certainly, we acknowledge that SES factors were not the focus of Fontan 3, and therefore it may seem unfair to critique the authors for the shortcomings of the analysis in this regard. Perhaps the message ought to be that future multi-institutional studies should include a more complete assessment of the influence of SES factors on outcomes given the increasing body of literature highlighting their importance.

\section{REGIONAL INITIATIVES TO ADDRESS HEALTH CARE DISPARITIES LINKED TO SES}

SES factors and health care disparities are primary drivers of outcome (especially for specific regions) within the highly resource-intense provision of complex congenital cardiac care. Implicit in this construct is an inherent obligation for collective efforts aimed at resolving these disparities and reducing these costs. It is perhaps predictable, then, that regional centers are beginning to cooperate in this endeavor. One such collaborative, the Southwest Congenital Cardiac Consortium, has leveraged the participation of all major medical centers in the Southwest providing pediatric cardiac surgery services to address critical health care disparities in the region. This group integrates a multidisciplinary team of congenital cardiac care providers to study processes of care at each center and 
engage government agencies to inform policies targeted at reducing disparities that impede access to value-based programs and increasing safety nets. Such initiatives are ideally focused within regions of the United States with high SES diversity and widespread health care inequities, such as California and the Southwest region. In Arizona, 51\% of children (more than 793,000) live below poverty level (US household income $\$ 48,000$ ) compared with a national average of $44 \% .{ }^{24}$ Congenital cardiac conditions and their complications also present a serious economic hardship on the State of California, with approximately $\$ 85,000,000$ in California Children's Services expenditures annually just on cardiac patients younger than age 1 year. ${ }^{24}$ Moreover, lack of access or incomplete capture to prenatal care and California Children's Services-mandated high-risk infant follow-up programs, by our estimates, increases direct costs to $\$ 7,360,441$ per year for noncaptured infants. Our efforts in the Southwest were inspired and informed by the successful regional precedents in adult cardiac surgery, such as the Michigan Blue Cross and Keystone collaboratives, ${ }^{25-28}$ and we anticipate that parallel regional and even national initiatives will follow.

\section{RESOLVING THE FONTAN PARADOX}

In the end, it is striking that in this large, multicenter longitudinal cohort of more than 300 Fontan survivors, SES factors emerged as more influential than those demographic and morphologic factors traditionally associated with outcome- a critical fact because these factors have been the subject of intense investigation and clinical focus. Whereas income or SES status are not modifiable per se, the mandate in our specialty for resolution of health care inequities is predicated on the likely presumption that lower SES underlies reduced access to critical perioperative programs and protocol-driven follow-up. Fatalists may accept the idea articulated by Malcolm Gladwell: "Who we are cannot be separated from where we're from." ${ }^{29}$ In other words, people exist forever within the limited confines of their initial social position. Readers of this important work by Atz and colleagues ${ }^{1}$ may likewise accept the inevitable attrition in functional status and survival of Fontan patients over time, but as stewards of the care of our growing single-ventricle population, we must transcend this passivity and move beyond description and prediction. We ought to, instead, move beyond the paradox implicit in this study, and act to develop regional and national infrastructure that can resolve disparity and foster pragmatic and equitable health care delivery paradigms.

\section{Conflict of Interest Statement}

Authors have nothing to disclose with regard to commercial support.
The authors thank the member providers and hospital systems within the Southwest Congenital Cardiac Consortium, which include:

Reshmi Binwale, MD, Brian Reemsten, MD, and Myke Federman, MD (University of California, Los Angeles, Calif); Anita Moon-Grady, MD, Sarah Tabbutt, MD, PhD, and Shabnam Peyvandi, MD (Benioff Children's Hospital, University of California, San Francisco, Calif); S. Ram Kumar, MD, PhD, Jay Pruetz, MD, Grace Kung, MD, and Nancy Pike, PhD (Children's Hospital Los Angeles, Los Angeles, Calif); Donna Goff, MD, and Anees Razzouk, MD (Loma Linda Medical Center, Loma Linda, Calif); Andrew Shin, MD, Frank Hanley, MD, Steve Roth, MD, and Kathy VanCamp (Lucille Packard Children's Hospital, Palo Alto, Calif); John J. Nigro, MD, Raghav Murthy, MD, and John Lamberti, MD (Rady Children's Hospital, University of California, San Diego, San Diego, Calif); Shaun Setty, MD (Miller Children's Hospital, Long Beach, Calif); Joanne Starr, MD, and Ahmad Reza Ellini, MD (Children's Hospital of Orange County, Orange County, Calif); Gary Raff, MD, and Stephanie Marie Falwell, BS (University of California Davis, Sacramento, Calif); and Tara Karamlou, MD, MSc (Phoenix Children's Hospital, Phoenix, Ariz).

\section{References}

1. Atz A, Zak V, Mahony L, Uzark K, D'agincourt N, Goldberg D, et al. Longitudinal outcomes of patients with single ventricle after the Fontan procedure. J Am Coll Cardiol. 2017;69:2735-44.

2. Mascio CE, Pasquali SK, Jacobs JP, et al. Outcomes in adult congenital heart surgery: analysis of the Society of Thoracic Surgeons Database. J Thorac Cardiovasc Surg. 2011;142:1090-7.

3. Crossland DS, Jackson SP, Lyall R, et al. Employment and advice for careers for adults with congenital heart disease. Cardiol Young. 2005;15:391-5.

4. Forsdick V, Jyengar AJ, Carins T, et al. Unsatisfactory outcomes after Fontan surgery delayed to adolescence and adulthood. Semin Thorac Cardiovasc Surg. 2015;27:168-74.

5. Castellanos DA, Herrigton C, Adler S, Haas K, Ram Kumar S, Kung GC. Home monitoring program reduces mortality in high-risk sociodemographic singleventricle patients. Pediatr Cardiol. 2016;37:1575-80.

6. Ghanayem NS, Allen KR, Tabbutt S, et al. Interstage mortality after the Norwood procedure: results of the multi-center single ventricle reconstruction trial. J Thorac Cardiovasc Surg. 2012;144:896-906.

7. Khoshnood B, Lelong N, Andrieu T, Houyel L, Bonnet D, Jouannic JM, et al. Assessing sociodemographic differences (or lack thereof) in prenatal diagnosis of congenital heart defects: a population-based study. BMJ Open. 2016;6:e009353.

8. Kempny A, Diller GP, Dimopoulos K, Alonso-Gonzalez R, Uebing A, Li W, et al. Determinants of outpatient clinic attendance amongst adults with congenital heart disease and outcome. Int J Cardiol. 2016;203:245-50.

9. Taylor LC, Burke B, Donohue JE, Yu S, Hirsch-Romano JC, Ohye RG, et al. risk factors for interstage mortality following the Norwood procedure: impact of sociodemographic factors. Pediatr Cardiol. 2016;37:68-75.

10. Bornstein MH, Bradley RH. Socioeconomic status, parenting, and child development. In: Monographs in Parenting. Mahwah, NJ: Lawrence Erlbaum Associates; 2000:287.

11. Cassedy A, Drotar D, Ittenbach R, et al. The impact of socio-economic status on health related quality of life for children and adolescents with heart disease. Health Qual Life Outcome. 2013;11:99.

12. The American Heritage New Dictionary of Cultural Literacy. 3rd ed. New York: Houghton Mifflin Company; 2005.

13. Braveman PA, Cubbin C, Egerter S, Chideya S, Marchi KS, Metzler M, et al. Socioeconomic status in health research. One size does not fit all. JAMA. 2005;294: 2879-88.

14. McDonald CM, Karamlou T, Wengle JG, et al. Nutrition and exercise environment available to outpatients, visitors, and staff in Children's hospitals in Canada and the United States. Arch Pediatr Adolesc Med. 2006;160:900-5.

15. Oster ME, Strickland MJ, Mahle WT. Racial and ethnic disparities in postoperative mortality following congenital heart surgery. J Pediatr. 2011;159:222-6. 
16. Benavidez OJ, Gauvreau K, Jenkins KJ. Racial and ethnic disparities in mortality following congenital heart surgery. Pediatr Cardiol. 2006;27:321-8.

17. Wang Y, Liu G, Druschel CM, Kirby RS. Maternal race/ethnicity and survival experience of children with congenital heart disease. J Pediatr. 2013;163: $1437-42$.

18. Bellinger DC, Wypij D, Rivkin M, DeMaso DR, Robertson RL, DunbarMasterson C, et al. Adolescents with d-transposition of the great arteries corrected with the arterial switch procedure: neuropsychological assessment and structural brain imaging. Circulation. 2011;124:1361-9.

19. Poh CL, Zannino D, Weintraub RG, Winlaw DS, Grigg LE, Cordina R, et al. Three decades later: the fate of the population of patients who underwent the Atriopulmonary Fontan procedure. Int J Cardiol. 2017;231:99-104.

20. California Department of Health Care Services. California Children's Services. Available at: http://www.dhcs.ca.gov/Services/CCS/Pages/default.aspx. Accessed May 20, 2014.

21. Martinez SC, Byku M, Novak EL, et al. Increased body mass index is associated with congestive heart failure and mortality in adult Fontan patients. Congenit Heart Dis. 2016;11:71-9.

22. Assari S. Life expectancy gain due to employment status depends on race, gender, education, and their intersections. Racial Ethn Health Disparities. June 20, 2017 [Epub ahead of print].
23. Maslow AH. A theory of human motivation. Psychol Rev. 1943;50:370-96

24. Wise P. California Children's Services Program analysis final report. Stanford Center for Policy, Outcomes and Prevention. Stanford University; 2011. Available at: http://www.dhcs.ca.gov/services/ccs/Documents/CCSFinalReport06_ 30_11.pdf. Accessed April 24, 2016.

25. Barlow J, Davis H, McIntosh E, et al. Role of home visiting in improving parenting and health in families at risk of abuse and neglect: results of a multicenter randomized controlled trial and economic evaluation. Arch Dis Child. 2007;92:229-33.

26. O'Connor GT, Plume SK, Olmstead EM, et al. A regional intervention to improve the hospital mortality associated with coronary artery bypass graft surgery. The Northern New England cardiovascular disease study Group. JAMA. 1996;275 841-6.

27. Moscucci M, Share D, Kline-rogers E, et al. The blue cross blue shield of Michigan cardiovascular consortium (BMC2) collaborative quality improvement initiative in percutaneous coronary interventions. J Interv Cardiol. 2002;15:381-6.

28. Moscucci M, Rogers EK, Montoye C, et al. Association of a continuous quality improvement initiative with practice and outcome variations of contemporary percutaneous coronary interventions. Circulation. 2006;113:814-22.

29. Gladwell M. Outliers: The Story of Success. New York: Little, Brown, and Company; 2008 . 